\title{
A COMPARISON OF INTRAMUSCULAR DEXMEDETOMIDINE AND INTRAMUSCULAR KETAMINE FOR PREMEDICATION IN PEDIATRIC ANESTHESIA: A DOUBLE-BLINDED RANDOMIZED CLINICAL TRIAL
}

\author{
Sabin Bhandari, ${ }^{1{ }^{*}}$ Balkrishna Bhattarai, ${ }^{1}$ Birendra Prasad Sah, ${ }^{1}$ Ashish Subedi, ${ }^{1}$ Prakash Poudel, ${ }^{2}$ Jagat Narayan Prasad ${ }^{2}$
}

${ }^{1}$ Department of Anesthesiology and critical care, ${ }^{2}$ Department of Pediatrics \& Adolescent Medicine, B.P. Koirala Institute of Health Sciences, Dharan, Nepal

*Correspondence to: Dr Sabin Bhandari, Department of Anaesthesiology and Critical Care, B.P. Koirala Institute of Health Sciences, Dharan, Nepal.

Email address: Sabin7000@gmail.com

\begin{abstract}
Background: Preoperative anxiety is often associated with negative perioperative consequences. In this study we compared intramuscular dexmedetomidine, a newer $\alpha 2$ agonist with more commonly used intramuscular ketamine for premedication in pediatric anesthesia.Methods: Sixty children, aged 1 to 10 years, undergoing surgery under general anesthesia, were enrolled for this prospective randomized double-blind clinical trial. Group A ( $n=30)$ received $2 \mathrm{mg} / \mathrm{kg}$ ketamine intramuscularly and group B $(\mathrm{n}=30)$ received $2 \mathrm{mcg} / \mathrm{kg}$ dexmedetomidine intramuscularly $15 \mathrm{~min}$ before induction of anesthesia. Preoperative anxiety and sedation were assessed using modified Yale Preoperative Anxiety Scale and Ramsay Sedation Scale respectively for $15 \mathrm{~min}$ at $5 \mathrm{~min}$ interval. All the patients were then anesthetized and the hemodynamic response and any adverse events intraoperatively and postoperatively were noted. Results: Reduction in incidence of severe anxiety was comparable in both the groups after 15 min of premedication (70\% in group $A$ vs $33.4 \%$ in group $B$ at 5 min, $p<0.001,80 \%$ in group $A$ vs $70 \%$ in group $B$ at 10 min, $p=0.088,80 \%$ in group $A$ vs $76.7 \%$ in group $B$ at $15 \mathrm{~min}, p=0.644)$. Group $A$ patients were more sedated than group $B$ patients $(6.7 \%$ in group $A$ vs $0 \%$ in group $B$ at 5 min, $p=0.150,63.3 \%$ in group $A$ vs $16.7 \%$ in group $B$ at 10 min, $p<0.001,76.7 \%$ in group $A v s 16.7 \%$ in group $B$ at 15 min, $p<0.001$ ). Conclusion: Intramuscular dexmedetomidine provides comparable anxiolysis with less sedation than intramuscular ketamine as premedicant in pediatric patients.
\end{abstract}

Keywords: Dexmedetomidine, Ketamine, Pediatric anesthesia, Premedication

\section{INTRODUCTION}

Perioperative anxiety in children can cause several physiological and behavioral complications intraoperatively as well as postoperatively which can last several days to weeks. ${ }^{1}$ It begins as soon as the surgical procedure is planned and increases to maximal intensity, the moment the child enters the hospital. ${ }^{2}$ Therefore, it is essential to treat anxiety before surgery in children.

Even though a number of strategies have been tried for paediatric anxiolysis at induction of anaesthesia or separation from parents and found to be effective, however, not all are logistically feasible or even appropriate in resource constraint settings. ${ }^{3}$ Neverthless, pharmacologic premedication is not only exceedingly effective but also feasible in most of the settings. ${ }^{4}$

Though premedication is common, there is no widely accepted consensus on drug regimens and routes with each having their own merits and drawbacks. ${ }^{5,6}$ Intramuscular (IM) medications, though cause minimal pain and discomfort at the site of injection, are, however, easy to administer, effective and have a good bioavailability. 7

Intramuscular ketamine $(2-4 \mathrm{mg} / \mathrm{kg})$ combined with atropine $(0.02 \mathrm{mg} / \mathrm{kg})$ is generally used for children who refuse oral premedication, those in whom lighter premedication regimens have failed in the past or those with anticipated difficult venous access. ${ }^{7}$ It is being successfully used widely as a premedication due to the ease of administration and effectiveness without any significant side effects or complications. 
Dexmedetomidine is a highly selective newer agonist of $\alpha 2$-adrenergic receptors 8 which has demonstrated sedative, analgesic, anxiolytic, decongestant, antisialagogue, antishivering and antiemetic effects after administration to volunteers and postsurgical patients. ${ }^{9,10,11,12}$ Dexmedetomidine injected intramuscularly has also shown sedative and anxiolytic effects in adults and children. ${ }^{13,14,15,16}$

Reports of studies comparing intramuscular ketamine and dexmedetomidine as premedicants in children are lacking or sparse in the literature. Therefore, the present study aimed to compare intramuscular dexmedetomidine with intramuscular ketamine for preoperative anxiolysis and sedation in children before induction of anesthesia.

\section{METHOD}

Sixty American Society of Anesthesiologist (ASA) physical status I children, aged 1 to 10 years, undergoing surgery under general anaesthesia were enrolled in this prospective, randomized, doubleblind, clinical trial after obtaining ethical clearance from the Institutional Ethical Review Board (IERB) of B. P. Koirala Institute of Health Sciences

(BPKIHS) (IERB/287/014) and written informed consent from the parents of each enrolled children. The children were randomly assigned into two groups, ketamine group (group $K, n=30$ ) and dexmedetomidine group (group $\mathrm{D}, \mathrm{n}=30$ ) via a computer generated random number sequence.

Children with history of allergy or hypersensitivity reaction to dexmedetomidine or ketamine and atropine, cardiac arrhythmia or congenital heart diseases, active upper respiratory tract infection within previous two weeks or having known lung disease or airway abnormalities, seizure disorder or mental retardation or under any medications that can provoke seizures, and those taking medications that can cause hypotension and bradycardia were excluded from the study. The study was conducted from 31st June, 2014 to 1st July, 2015 in the Routine Operation Theatre complex of BPKIHS.

The sample size was calculated based on finding of studies by McGlone et al.17 who observed percentage of children who were sedated with ketamine $2 \mathrm{mg} / \mathrm{kg}$ IM to be $90.3 \%$ and Mason et al.16 who observed adequate sedation in $55 \%$ of children given dexmedetomidine $2.4 \mathrm{mcg} / \mathrm{kg}$ IM. A power of $80 \%$, alpha value of 0.05 , and the percentage of children who were adequately sedated on both groups were taken for calculation and the sample size was calculated to be 25 for each group. To compensate for the possible dropouts, 30 children were enrolled in each group.

All the enrolled children were kept fasting according to standard pediatric fasting guidelines and not premedicated on the night before surgery. Baseline systolic and diastolic blood pressure together with heart rate was noted as the mean of two readings taken 5 min apart on the day before surgery in respective wards where the child was admitted. On arrival to the preoperative holding area, each child was assessed for anxiety and sedation prior to intervention by modified Yale Preoperative Anxiety Scale ${ }^{18,19}$ and Ramsay Sedation Scale ${ }^{20,21}$ respectively by the investigator responsible for observing the outcome. A modified Yale Preoperative Anxiety Scale score below 30 indicated no anxiety, between 30 and 70 indicated some anxiety and above 70 indicated very anxious children. A minimum Ramsay Sedation Score of 4 was accepted as adequate sedation. Oxygen, suction facilities, self inflating resuscitation bag and mask, equipment for intubation, and drugs for resuscitation was made available at all times. A pulse oximeter probe was connected throughout the procedure. The study medications were then administered intramuscularly into the gluteal muscle via a $25 \mathrm{G}$ needle by an anaesthesia assistant not involved in the study. Pulse rate and oxygen saturation ( $\mathrm{SpO} 2$ ) were recorded at the time of drug administration and at $2.5 \mathrm{~min}$ intervals up to $15 \mathrm{~min}$ after which anaesthesia was induced in the child. The preoperative anxiety score and sedation score were also evaluated every $5 \mathrm{~min}$ after study drug was given till full induction of anesthesia.

After 15 min of administration of study drugs, the child was shifted to the operating room and standard monitoring devices viz NIBP cuff, ECG leads, pulse oximeter probe were attached. Intravenous (IV) cannulation was attempted prior to induction of anaesthesia in adequately sedated and cooperative children. In inadequately sedated or anxious children on operation table, anaesthesia was induced with inhalation of halothane in oxygen and their peripheral IV access secured by an experienced anaesthesiologist. Subsequently IV glycopyrrolate 4 
$\mathrm{mcg} / \mathrm{kg}$ was administered in all the children. In children with already established IV access, anesthesia was induced with IV propofol $2.5 \mathrm{mg} / \mathrm{kg}$ and IV fentanyl $1.5 \mathrm{mcg} / \mathrm{kg}$. After achieving adequate depth of anesthesia, an appropriately sized laryngeal mask airway (LMA) was inserted as per the manufacturer's instructions. Anaesthesia was maintained with 1.0-2.0 MAC end-tidal concentration of isoflurane in $100 \%$ oxygen to maintain immobility and eucapnoea and intravenous bolus of fentanyl administered for analgesia as required. Hydration was provided with lactated Ringer's solution as per the standard protocol.

Hypotension was defined as a decrease of mean arterial pressure of more than $20 \%$ from the baseline readings and was treated with IV crystalloid fluid bolus of $10 \mathrm{ml} / \mathrm{kg}$. Similarly hypertension was defined as an increase of mean arterial pressure of more than $20 \%$ from the baseline readings and treated by increasing the percentage of inhalation agent. Bradycardia was defined as HR less than $20 \%$ of the baseline readings and treated with IV glycopyrrolate $4 \mathrm{mcg} / \mathrm{kg}$. Tachycardia was defined as HR more than $20 \%$ of the baseline readings and treated with IV fentanyl $0.5 \mathrm{mcg} / \mathrm{kg}$.

IV ondensetron $0.15 \mathrm{mg} / \mathrm{kg}$ was given $15 \mathrm{~min}$ prior to the end of the surgery. On completion of the surgery, isoflurane was discontinued and LMA removed on deeper plane of anaesthesia. The percentage requirement of isoflurane and intraoperative incidence of any adverse events were recorded. The child was then transferred to post anaesthetic care unit and a registered nurse blinded to the study monitored the vitals and nausea, vomiting, shivering and any other post operative complications. The children were discharged after they attained the modified Aldrete score of 9.

The data collected was entered into MS excel software 2007 and exported it into SPSS (Statistical Package for Social Science - 11.5) for statistical analysis. For normally distributed data, Unpaired and Paired Student-t test, for non-normally distributed data, Unpaired and Paired Student-t test, for non-normally distributed data, Wilcoxan Signed Rank test and Mann Whitney $U$ test and for proportion, Chi-square test and Fishers exact test were applied to find out significant difference among and between the groups at $95 \%$ confidence interval where $p=0.05$. For descriptive statistics, mean, S.D., percentage, proportion, median, interquartile range were calculated wherever applicable.

\section{RESULTS}

Sixty patients were enrolled, randomized and analyzed in the study, 30 in group $\mathrm{K}$ (ketamine) and 30 in group D (dexmedetomidine). (Figure 1)

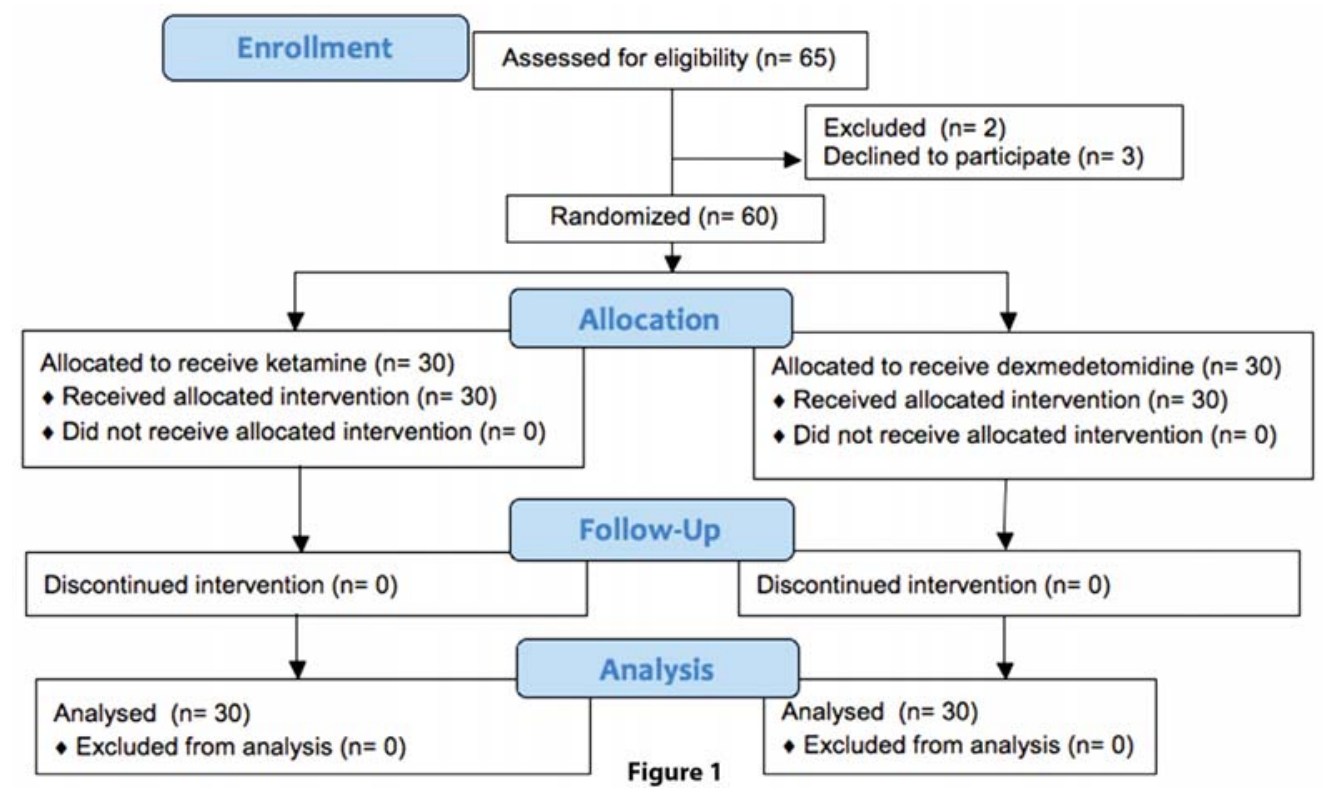

Figure 1: Flow diagram of study 
Baseline demographic characteristics are shown in table 1 and are comparable in both the groups.

Table 1: Comparison of demographic characteristics between the two groups

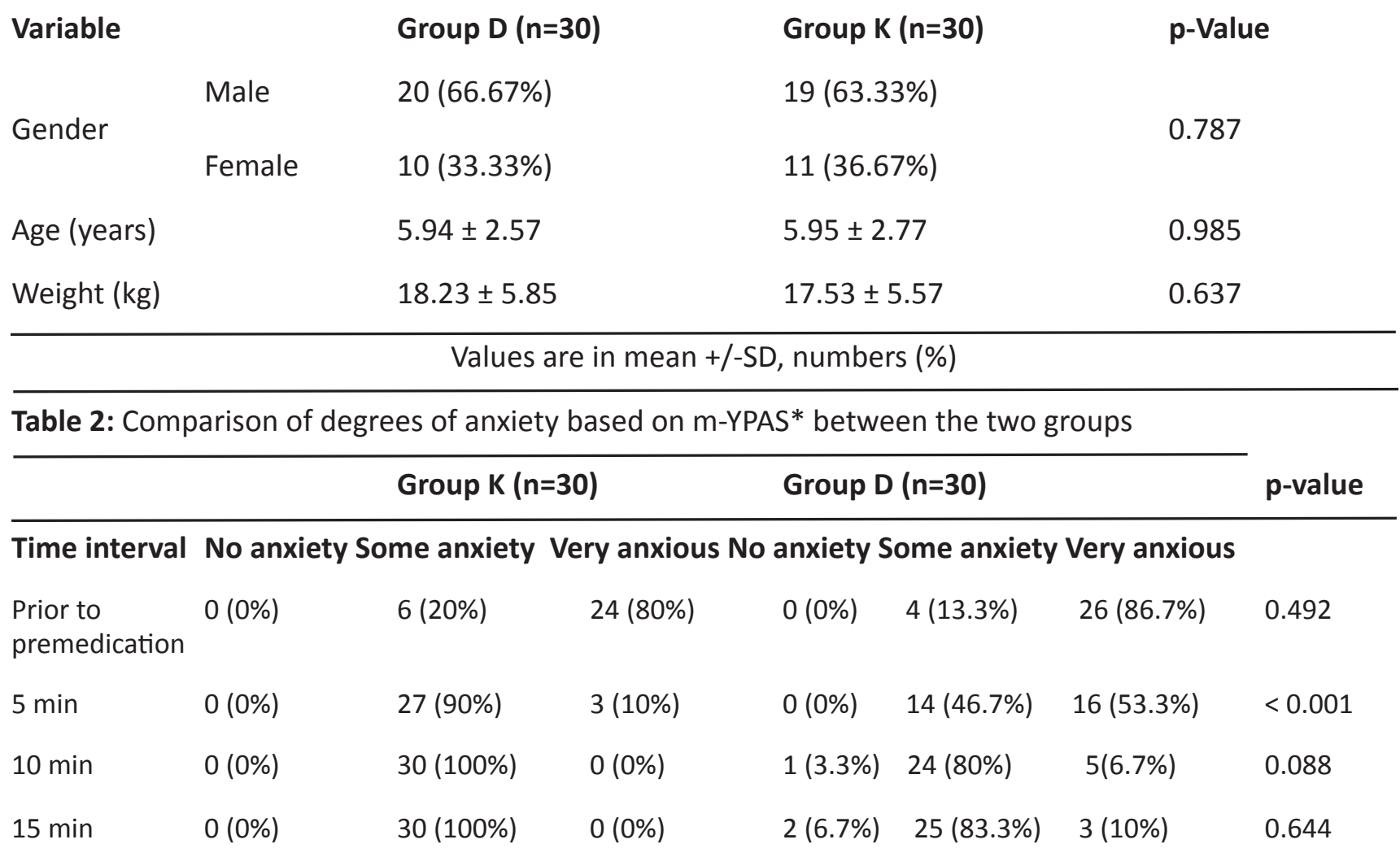

Values are in numbers (\%)

*m-YPAS - modified Yale Preoperative Anxiety Scale

When data were analyzed within each group, in group $\mathrm{K}$, there was a decrease in, m-YPAS after 5 min, 10 min and $15 \mathrm{~min}$ from baseline prior to premedication. This difference in rank was statistically significant $(p<$ 0.05 ) at all point of measurement after premedication. Similar trend was also found in group D.

Table 3: Comparison of degrees of sedation score (RSS*) between the two groups

\begin{tabular}{|c|c|c|c|c|c|}
\hline \multirow[b]{2}{*}{ Time interval } & \multicolumn{2}{|l|}{ Group K $(n=30)$} & \multicolumn{2}{|l|}{ Group D $(n=30)$} & \multirow{2}{*}{ p-value } \\
\hline & $\begin{array}{l}\text { Not adequately } \\
\text { sedated (RSS }<4)\end{array}$ & $\begin{array}{l}\text { Adequately } \\
\text { sedated (RSS } \geq 4 \text { ) }\end{array}$ & $\begin{array}{l}\text { Not adequately } \\
\text { sedated (RSS }<4)\end{array}$ & $\begin{array}{l}\text { Adequately } \\
\text { sedated (RSS } \geq 4 \text { ) }\end{array}$ & \\
\hline $\begin{array}{l}\text { Prior to } \\
\text { premedication }\end{array}$ & 30 (100\%) & $0(0 \%)$ & 30 (100\%) & $0(0 \%)$ & - \\
\hline $5 \mathrm{~min}$ & $28(93.3 \%)$ & $2(6.7 \%)$ & $30(100 \%)$ & $0(0 \%)$ & 0.154 \\
\hline $10 \mathrm{~min}$ & $11(36.7 \%)$ & 19 (63.3\%) & 25 (83.3\%) & $5(16.7 \%)$ & $<0.001$ \\
\hline $15 \mathrm{~min}$ & $7(23.3 \%)$ & 23 (76.7\%) & 25 (83.3\%) & $5(16.7 \%)$ & $<0.001$ \\
\hline
\end{tabular}

Values are in numbers (\%)

*RSS - Ramsay Sedation Score 
When data were analyzed within each group, in group $K$, there was no significant difference in sedation after premedication for the first $5 \mathrm{~min}(p=0.157)$, but there was an increase in sedation after $10 \mathrm{~min}$ and $15 \mathrm{~min}$, which was statistically significant $(p<0.001)$. Similar trend was also found in group D.

The mean heart rate at baseline was comparable between the two groups $(p=0.544)$. Thereafter the mean heart rates between the two group after premedication at various time interval were statistically comparable ( $p$ value $>0.05$ ) though group $\mathrm{K}$ patients had slightly higher rates as compared to group D patients. However, after induction of anesthesia, the heart rates were significantly higher at all observation points in group $\mathrm{K}$ as compared to group $D(p<0.05)$ (Figure 2$)$.

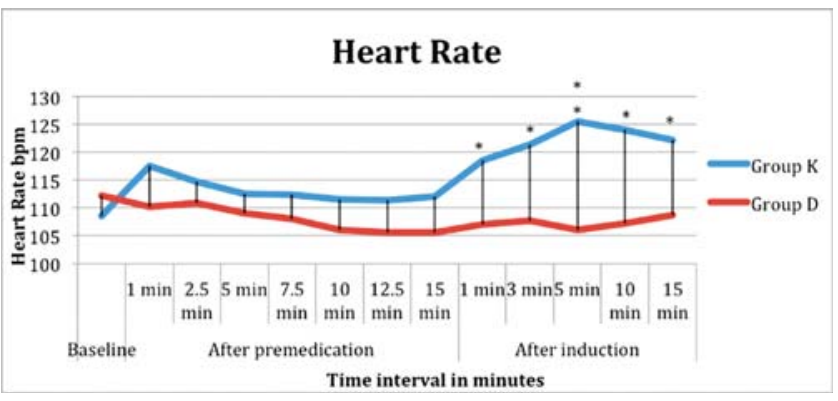

Fig. 2: Comparison of mean heart rates (bpm) between the two groups The average mean arterial pressure at baseline was significantly less in group $D$ than in the group $K(p=$ $0.037)$. After that average mean arterial pressure was comparable between the two groups ( $p$ value $>0.05$ ) at all time points of measurement (Figure 3 ).

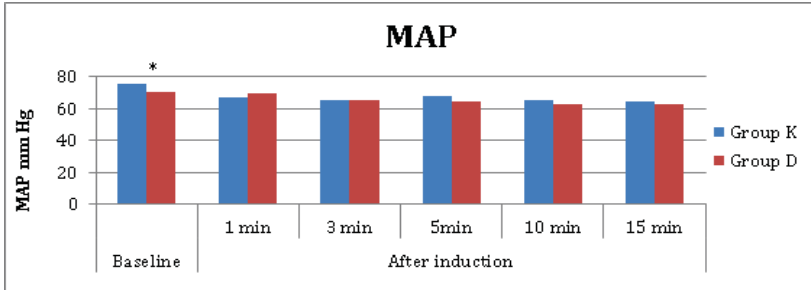

Time interval in minutes

Fig 3: Comparison of MAP measurements between the two groups at different points of measurements.

The mean percentage of isoflurane requirement was comparable between the two groups ( $p$ value $>0.05$ ) at all points of measurement.

In terms of adverse events, shivering was observed in one patient and laryngospasm in two patients in the postoperative period in group $\mathrm{K}$. Both cases were managed successfully with the local protocols. There were no incidence of postoperative nausea and vomiting
DISCUSSION

In our study, we found that both dexmedetomidine and ketamine when given intramuscularly provided comparable anxiolysis. Regarding sedative effects, we found ketamine to be a better sedative than dexmedetomidine at 10 and $15 \mathrm{~min}$ after administration in children undergoing surgery under general anesthesia. In literature search, we did not find any study with the study design similar to ours for close comparison with our findings. Three studies compared dexmedetomidine and ketamine for their sedative effect in children.

Singh et al.22 compared the analgo-sedative effects of oral dexmedetomidine and ketamine in a tripleblind, randomized study and found that the onset of sedation was significantly rapid with ketamine $8 \mathrm{mg} /$ $\mathrm{kg}$ and $5 \mathrm{mcg} / \mathrm{kg}$ of dexmedetomidine as compared to $3 \mathrm{mcg} / \mathrm{kg}$ and $4 \mathrm{mcg} / \mathrm{kg}$ of dexmedetomidine. Our study differs from this study not only in terms of route of administration but also in dose of the drugs used to premedicate the children. We used intramuscular route and lower doses; ketamine in a dose of $2 \mathrm{mg} / \mathrm{kg}$ and dexmedetomidine in a dose of $2 \mathrm{mcg} / \mathrm{kg}$.

Ibrahim23 compared the effects of intranasal dexmedetomidine $3 \mu \mathrm{g} / \mathrm{kg}$ with intranasal ketamine 7 $\mathrm{mg} / \mathrm{kg}$ for procedural sedation in school aged children undergoing MRI and observed that children treated with ketamine achieved faster sedation at $10 \mathrm{~min}$ point with $\mathrm{P}<0.05$ and comparable sedation to those treated with dexmedetomidine at 20 and $30 \mathrm{~min}$ respectively. Again the route of drug administration and dose of study were different from our study. The investigator in this study used higher dose of both study drugs as compared to our study.

Gyanesh et al.24 compared intranasal dexmedetomidine $1 \mathrm{mcg} / \mathrm{kg}$ and intranasal ketamine $5 \mathrm{mg} / \mathrm{kg}$ and found that $90.4 \%$ of the anesthesiologists in dexmedetomidine treated group and $82.7 \%$ of the anesthesiologists in the ketamine treated group were satisfied with the conditions for IV cannulation thus concluding both drugs to be equally efficacious as premedicant in children undergoing MRI. Though they used the same drugs in their study as ours, there are several differences in the design and outcome variables between theirs and our study. In our study, we used intramuscular route as route of drug administration and higher dose of dexmedetomidine and lower dose of ketamine. . Further, our study did 
not compare anesthesiologist's acceptance.

All the above three studies reported comparable sedation success rates between ketamine and dexmedetomidine, which is different from our own findings. We found only $16.7 \%$ of patients to be adequately sedated by our definition in dexmedetomidine treated children as compared to $76.7 \%$ in ketamine treated children. The time allowed in different studies for the premedicants before induction of general anesthesia most plausibly explains the difference. Singh et al.22 allowed adequate sedation before induction, Ibrahim 23 allowed $30 \mathrm{~min}$ for premedication before induction of anesthesia and Gyanesh et al.24 allowed 60 min for premedication. Those are much longer than only 15 min before induction of anesthesia in our case.

Our basis of allowing 15 min for premedication was based on the works of Mason et al.18 who observed mean time to achieve sedation with intramuscular dexmedetomidine $2.9 \mu \mathrm{g} / \mathrm{kg}$ in the children undergoing $\mathrm{MRI}$, and $2.4 \mu \mathrm{g} / \mathrm{kg}$ in children undergoing CT to be 13.1-13.4 min. Further, we assumed that a higher bioavailability of study drugs achieved with the intramuscular route would allow faster sedation of children. However, our study showed that though the onset of sedation with dexmedetomidine was observed from $10 \mathrm{~min}$ of premedication, most of the children were not adequately sedated even at the end of 15 min suggesting longer time for peak effect of dexmedetomidine with the intramuscular route.

In literature search, we did not find any previous study directly comparing the anxiolytic effect of ketamine and dexmedetomidine. Instead we found them being compared with oral midazolam for anxiolytic effect in children.

Alderson and Lerman 25 and Sen et al.26 compared oral ketamine $5 \mathrm{mg} / \mathrm{kg}$ and oral midazolam $0.5 \mathrm{mg} /$ $\mathrm{kg}$ for pediatric ambulatory anesthesia and found similar or superior anxiolysis with oral ketamine. They inferred an interval of 20 min to be sufficient between premedication and parental separation.

Our findings compares with the findings of Alderson and Lerman 25 and Sen et al.26 by demonstrating good anxiolysis in children treated with ketamine with fast onset and consistency in anxiolysis score
(90\% anxiolysis at $5 \mathrm{~min}$ following premedication). However, there are differences in the design of their and our study. We used intramuscular route and observed sufficient anxiolysis in children in $15 \mathrm{~min}$.

A meta-analysis by Peng et al.27 investigating the role of dexmedetomidine as a premedicant for pediatric patients including thirteen randomized controlled trials involving 1190 patients found premedication with dexmedetomidine to result in more satisfactory separation from parents as compared to midazolam ( $\mathrm{RD}=0.18,95 \% \mathrm{Cl}: 0.06$ to $0.30, \mathrm{p}=0.003$ ).

Our findings are similar to the meta-analysis in eliciting the anxiolytic effect of dexmedetomidine. However, unlike our findings, the meta-analysis has shown dexmedetomidine to be a good sedative. The reason for this discrepancy could be the time allowed for the patients after premedication before induction of general anesthesia. In our study, we allowed $15 \mathrm{~min}$ after premedication before inducing general anesthesia whereas in the studies included in the meta-analysis, the time of intervention and dosing varied between $30 \mathrm{~min}$ to $60 \mathrm{~min}$. This longer time interval may have allowed dexmedetomidine to exhibit its sedative effect in these studies. The other explanation could be that though dexmedetomidine exhibits sedation, the patients are easily arousable, thus, limiting the level of sedation achieved as "adequately sedated," defined in our study as Ramsay Sedation Score $\geq 4$. Also, the study design differed in that we used intramuscular route for premedication, and others have used intranasal, oral, trans mucosal, and sublingual route and there have been no studies suggesting the equivalent dosing of dexmedetomidine through various routes.

In our study, we found that there was a significant difference in anxiolysis between the two arms in our study for the first 5 minutes, after which the anxiolysis between the two study groups was comparable. On comparing anxiolysis within each group, our study further revealed that anxiolytic effect significantly increased with time in both the groups. The discrepancy between the two drugs can be explained by the faster onset of anxiolysis with ketamine as compared to dexmedetomidine. The comparable anxiolysis seen after 10 and 15 min of premedication in both the groups suggests good anxiolytic effects of both the drugs. 
and vomiting response postoperatively.

Even though oral route is the most preferable route for premedication, we decided to use intramuscular route for various reasons including unavailability of oral formulation of appropriate premedicants, the problem of children not swallowing or spitting out of the drug, delayed onset of action, which is likely to unnecessarily delay the surgery. Further, securing an intravenous access for IV sedation can be difficult in struggling and boisterous children in the preoperative room and they may be made more upset by introducing the drug into their nose and rectums rather than by an intramuscular injection.

We observed no significant difference in heart rates between the two drugs before induction during our observation period of $15 \mathrm{~min}$. After induction of anesthesia, we found that children premedicated with dexmedetomidine had lesser change in heart rate when compared with preinduction and baseline heart rate. On the other hand, children premedicated with ketamine had a significant increase in heart rate when compared with baseline heart rate. We attribute this finding to the attenuating effect of dexmedetomidine13 to LMA insertion. Though the mean MAP prior to induction of anesthesia was less in dexmedetomidine treated children than in ketamine treated children which we attribute to chance due to our relatively small sample size, however, the difference in MAP in between the two groups was not statistically significant. Further, children premedicated with dexmedetomidine required less isoflurane than those premedicated with ketamine but not to the level of statistical significance.

One child premedicated with ketamine developed shivering in postoperative recovery area. Two children premedicated with ketamine developed laryngospasm in the postoperative recovery room but was manageable with the application of continuous positive airway pressure. Both the children were not adequately sedated and we suspect increased secretions to have precipitated the condition.

Dexmedetomidine, is considered a weak antiemetic 10 but ketamine increases the incidence of postoperative nausea and vomitting. 28 However, our study showed no incidence of nausea and vomiting in either groups. This may be due to the fact that we gave IV ondansetron to all patients involved in the study intraoperatively, which may have attenuated the nausea
The major limitation in our study is the time allowed for premedication. We allowed only $15 \mathrm{~min}$ before inducing general anesthesia after premedication considering the time constraint and delay in starting the surgery. Had we allowed a longer period for premedication, our result for sedation could have been different. Similarly, we used intramuscular route which though is effective, but not ideal route of premedication in children. Similarly, the equivalent dosing is not available for ketamine and dexmedetomidine as well as among various routes of dexmedetomidine, which warrants further research in this direction.

\section{CONCLUSION}

The anxiolytic property of Intramuscular dexmedetomidine $2 \mathrm{mcg} / \mathrm{kg}$ is comparable with intramuscular ketamine $2 \mathrm{mg} / \mathrm{kg}$ but less effective as sedative in children premedicated for general anesthesia with attenuation of hemodynamic response to LMA insertion and lesser adverse events as compared to ketamine.

Informed consent: Informed consent was obtained from all the parents whose children were included in the study.

Conflicts of interest: None

Acknowledgement: None

Sources of funding: None

\section{REFERENCES:}

1. Kain ZN, Mayes LC, O'Connor TZ, Cicchetti DV. Preoperative anxiety in children. Predictors and outcomes. Arch Pediatr Adolesc Med 1996;150:1238-1245. [PMID: 8953995]

2. Klopfenstein CE, Forster A, Van Gessel E. Anesthetic assessment in an outpatient consultation clinic reduces preoperative anxiety. Can J Anaesth 2000;47:511-515. http://dx.doi.org/10.1007/ BF03018941 [PMID: 10875713]

3. Yip P, Middleton P, Cyna AM, Carlyle AV. Nonpharmacological interventions for assisting the induction of anaesthesia in children (review). Cochrane Database Syst Rev 2009;3:CD006447. http://dx.doi.org/10.1002/14651858.CD006447. 
pub2 [PMID: 19588390]

4. Lerman J. Preoperative assessment and premedication in paediatrics (review). Eur J Anaesthesiol 2013;30:645-650. http://dx.doi. org/10.1097/EJA.0b013e328360c3e2 [PMID: 24022595]

5. Coté CJ, Notterman DA, Karl HW, Weinberg JA, McCloskey C. Adverse sedation events in pediatrics: a critical incident analysis of contributing factors. Pediatrics 2000;105:805-814. [PMID: 10742324]

6. Sanborn PA, Michna E, Zurakowski D, Burrows PE, Fontaine PJ, Connor L, et al. Adverse cardiovascular and respiratory events during sedation of pediatric patients for imaging examinations. Radiology 2005;237:288-294. http://dx.doi.org/10.1148/ radiol.2371041415. [PMID: 16183936]

7. Cote CJ. Pediatric Anesthesia. In: Miller RD, Eriksson IL, Fleisher LA, Wiener-Kronish JP, Young WL, editors. Miller's Anesthesia, 7th ed. Philadelphia: Churchill Livingstone, 2010:25742575.

8. Virtanen R, Savola JM, Saano V, Nyman L. Characterization of the selectivity, specificity and potency of dexmedetomidine as an alpha 2- adrenoreceptor agonist. Eur J Pharmacol 1988;150:9-14. [PMID: 2900154]

9. Gertler R, Brown HC, Mitchell DH, Silvius EN. Dexmedetomidine: a novel sedative-analgesic agent. Proc (Bayl Univ Med Cent) 2001;14:13-21. [PMID: 16369581]

10. CandiottiKA, BergeseSD, BokeschPM, FeldmanMA, Wisemandle W, Bekker AY. Monitored Anesthesia Care with Dexmedetomidine: A Prospective, Randomized, Double Blind, Multicenter Trial. Anesth Analg 2010;110:47-56. http://dx.doi. org/10.1213/ane.0b013e3181ae0856 [PMID: 19713256]

11. Guo TZ, Jiang JY,Buttermann AE, Maze $M$. Dexmedetomidine injection into the locus ceruleus produces antinociception. Anesthesiology 1996;84:873-881. [PMID: 8638842]

12. Talke P, Tayefeh F, Sessler DI, Jeffrey R, Noursalehi
M, Richardson C. Dexmedetomidine does not alter the sweating threshold, but comparably and linearly decreases the vasoconstriction and shivering thresholds. Anesthesiology 1997;87:835841. [PMID: 9357885]

13. Scheinin H, Jaakola ML, Sjovall S, Ali-Melkkilä T, Kaukinen S, Turunen J, et al. Intramuscular dexmedetomidine as premedication for general anesthesia. A comparative multicenter study. Anesthesiology 1993;78:1065-1075. [PMID: 8512099]

14. Erkola O, Korttila K, Aho M, Haasio J, Aantaa $\mathrm{R}$, Kallio A. Comparison of intramuscular dexmedetomidine and midazolam premedication for elective abdominal hysterectomy. Anesth Analg1994;79:646-653. [PMID: 7943770]

15. Karaaslan D, Peker TT, Alaca A,Ozmen S, Kirdemir $\mathrm{P}$, Yorgancigil $\mathrm{H}$, et al. Comparison of buccal and intramuscular dexmedetomidine premedication for arthroscopic knee surgery. J Clin Anesth 2006;18:589-593. http://dx.doi.org/10.1016/j. jclinane.2006.03.019 [PMID: 17175428]

16. Mason KP, Lubisch NB, Robinson F, Roskos R. Intramuscular Dexmedetomidine Sedation for Pediatric MRI and CT. AJR Am J Roentgenol 2011;197:720-725. http://dx.doi.org/10.2214/ AJR.10.6134 [PMID: 21862817]

17. McGlone RG, Howes MC, Joshi M. The Lancaster experience of 2.0 to $2.5 \mathrm{mg} / \mathrm{kg}$ intramuscular ketamine for paediatric sedation: 501 cases and analysis. Emerg Med J 2004;21:290-295. [PMID: 15107365]

18. Kain Z, Mayes L, Cicchetti D, Caramico LA, Spieker $\mathrm{M}$, Nygren $\mathrm{MM}$, et al. A measurement tool for pre operative anxiety in children: the Yale preoperative anxiety scale. Child Neuropsychol 1995;1:203-210. http://dx.doi.org/10.1080/09297049508400225

19. Kain ZN, Mayes LC, Cicchetti DV,Bagnall AL, Finley JD, Hofstadter MB. The Yale preoperative anxiety scale: how does it compare with a 'gold standard'? Anesth Analg 1997;85:783-788. [PMID: 9322455]

20. Mason KP, Michna E, Zurakowski D, Burrows PE, Pirich MA, Carrier M, et al. Value of bispectral index 
Bhandari et al, Journal of Chitwan Medical College 2017; 7(22)

monitor in differentiating between moderate and deep Ramsay sedation scores in children. Paediatr Anaesth 2006;16:1226-1231. http://dx.doi. org/10.1111/j.1460-9592.2006.01975.x [PMID: 17121551]

21. Mason KP, Zgleszewski SE, Dearden JL, Dumont RS, Pirich MA, Stark CD, et al. Dexmedetomidine for pediatric sedation for computed tomography imaging studies. Anesth Analg 2006;103:57-62. http://dx.doi.org/10.1213/01. ane.0000216293.16613.15 [PMID: 16790626]

22. Singh C, Pandey RK, Saksena AK, Chandra G. A comparative evaluation of analgo-sedative effects of oral dexmedetomidine and ketamine: a triple-blind, randomized study. Paediatr Anaesth 2014;24:1252-1259. http://dx.doi.org/10.1111/ pan.12493 [PMID: 25065424]

23. Ibrahim M. A prospective, randomized, double blinded comparison of intranasal dexmedetomodinevs intranasal ketamine in combination with intravenous midazolam for procedural sedation in school aged children undergoing MRI. Anesth Essays Res 2014;8:179$186 . \quad$ http://dx.doi.org/10.4103/02591162.134495 [PMID: 25886223]

24. Gyanesh P, Haldar R, Srivastava D, Agrawal PM, TiwariAK,SinghPK.Comparison between intranasal dexmedetomidine and intranasal ketamine as premedication for procedural sedation in children undergoing MRI: a double-blind, randomized, placebo-controlled trial. J Anesth 2014;28:12-18. http://dx.doi.org/10.1007/s00540-013-1657-x [PMID: 23800984]

25. Alderson PJ. Lerman J. Oral premedication for paediatric ambulatory anaesthesia: a comparison of midazolam and ketamine. Can J Anaesth 1994;41:221-226. http://dx.doi.org/10.1007/ BF03009834 [PMID: 8187256]

26. Sen S, Thakurta RG, Gupta SD, Bhattacharya $\mathrm{S}$, Mukherji S. Preoperative anxiolysis in pediatric population: A comparative study between oral midazolam and oral ketamine. Anesth Essays Res 2013;7:200-205. http:// dx.doi.org/10.4103/0259-1162.118960 [PMID: 25885833]

27. Peng K, Wu SR, Ji FH, Li J. Premedication with dexmedetomidine in pediatric patients: a systemic review and meta-analysis. Clinics ( Sao Paulo) 2014;69:777-786. http://dx.doi.org/10.6061/ clinics/2014(11)12 [PMID: 25518037]

28. Heinz P, Geelhoed GC, Wee C, Pascoe EM. Is atropine needed with ketamine sedation? A prospective, randomized, double blind study. Emerg Med J. 2006;23:206-209. http://dx.doi. org/10.1136/emj.2005.028969 [PMID: 16498158] 